\title{
A DECISÃO DA SUPREMA CORTE DOS ESTADOS UNIDOS SOBRE O SUICÍDIO ASSISTIDO: WASHINGTON V. GLUCKSBERG
}

\section{Raphael Rego Borges Ribeiro*}

\section{Resumo:}

Neste artigo, estudou-se o caso Washington $v$ Glucksberg, no qual se discutia a constitucionalidade da criminalização do suicídio assistido. Usou-se o método historiográfico com consulta a fontes primárias. Observou-se que a SCOTUS por unanimidade não reconheceu uma liberdade constitucional genérica a cometer suicídio, afastando também o direito de ser assistido ao fazê-lo. Notou-se que a Corte não debateu dignidade nem autonomia, focando majoritariamente no tratamento histórico da matéria e nos interesses estatais que justificavam a proibição. Concluiu-se que a Corte deu aos estados a responsabilidade de legislar sobre o suicídio assistido, mantendo assim a constitucionalidade da lei de Washington.

\section{Palavras-chave:}

Suicídio assistido; bioética; Suprema Corte dos Estados Unidos; morrer com dignidade; biodireito.

\section{THE SUPREME COURT OF THE UNITED STATES DECISION ON ASSISTED SUICIDE: WASHINGTON V. GLUCKSBERG}

\begin{abstract}
:
In this paper, I studied Washington $\mathrm{v}$ Glucksberg, a case in which the prohibition of physician-assisted suicide was discussed. I used the historiographic method, delving into primary sources. I saw that SCOTUS rejected a general constitutional liberty to commit suicide; the Court also rejected the right to be assisted in doing so. I noticed that SCOTUS did not discuss dignity nor autonomy, focusing mostly on both the historical treatment of the issue and the government interests that justified the ban. I concluded that the Court upheld the Washington law and gave the states the responsibility of regulating assisted suicide.
\end{abstract}

\section{Keywords:}

Assisted suicide; bioethics; Supreme Court of the United States; die with dignity; health law.

\section{INTRODUÇÃO}

Neste artigo, será observado Washington v. Glucksberg, um caso paradigmático julgado pela Supreme Court of the United States (SCOTUS), no qual a Corte se debruçou

\footnotetext{
* Bacharel, Mestre e Doutor em Direito pela Universidade Federal da Bahia. Pesquisou no Health Law Centre da University of Ottawa (Canadá). Professor de Direito Civil na Universidade Federal do Oeste da Bahia.
} 
sobre o suicídio assistido. Em muitas jurisdições, os debates mais profundos acerca da proteção aos direitos fundamentais acabam competindo ao Judiciário, no exercício da sua função contramajoritária e de controle de constitucionalidade; isso é verdade para o Brasil e também para os Estados Unidos.

A presente pesquisa se justifica em razão da sua contribuição para a divulgação à comunidade jurídica brasileira da jurisprudência constitucional norte-americana. A doutrina nacional costuma se referir a alguns poucos casos famosos decididos pela SCOTUS, como Brown v. Board of Education (sobre o racismo) e Roe v. Wade (sobre o direito ao aborto); todavia, ainda são muito incipientes as buscas por estudar julgados mais recentes, notadamente em outras matérias de direitos fundamentais. Ter contato profundo com casos paradigmáticos de uma das cortes constitucionais mais relevantes do mundo permite, entre outras coisas, buscar inspiração para futuros desenvolvimentos do direito pátrio, bem como analisar comparativamente com a própria história do direito no Brasil. Isso é particularmente verdade sobre a temática ora trabalhada, considerando o protagonismo assumido pelo Supremo Tribunal Federal e ao Superior Tribunal de Justiça em casos afins à bioética e ao biodireito. Este artigo pretende suprir esse gap, além de incentivar iniciativas semelhantes em outros temas.

O objetivo geral dessa investigação é descrever como a Suprema Corte estadunidense discutiu - e rejeitou - a existência de um direito constitucional ao suicídio e de ser assistido na prática de encerrar a própria vida. De forma específica, observaremos os fatos e o caminho do caso até a Suprema Corte; semelhantemente, destacaremos os principais fundamentos da opinião majoritária da corte e das opiniões concorrentes. Ao final, identificaremos na doutrina local críticas e repercussões da referida decisão para o ordenamento jurídico estadunidense. Este artigo tem uma natureza predominantemente descritiva; apesar de uma necessária investigação crítica mais aprofundada se fazer claramente cabível, isso aqui não é feito por razões de restrição de espaço. Acredita-se que a abordagem majoritariamente descritiva é consistente com o objetivo de pesquisa supramencionado.

Como método, será utilizada principalmente a técnica historiográfica, particularmente baseada na consulta às fontes primárias, quais sejam, os arquivos da SCOTUS, com a subsequente exposição dos argumentos utilizados no voto vencedor e nas opiniões concorrentes. Também se realizará consulta bibliográfica à doutrina especializada. 


\section{O CAMINHO ATÉ A SUPREME COURT OF THE UNITED STATES}

A legislação do estado de Washington criminalizava a assistência ao suicídio, ainda que esta fosse prestada por um médico buscando ajudar pacientes terminais em sofrimento; a lei previa uma pena de até 05 anos de prisão, além de multa de até 10 mil dólares, para quem praticasse tal conduta ${ }^{1}$. A Compassion in Dying $^{2}$, três pacientes anônimos ${ }^{3}$ e cinco médicos ${ }^{4}$ do estado de Washington decidiram questionar judicialmente a referida proibição, alegando que ela violaria um interesse protegido pela Due Process Clause da Décima Quarta Emenda à Constituição estadunidense ${ }^{5}$ - a liberdade de um adulto mentalmente capaz, acometido de uma doença terminal, de fazer a escolha pessoal no sentido de cometer suicídio com a assistência de um médico (WASHINGTON, 1997, p.702).

\section{A Judge Barbara Rothstein, da United States District Court for the Western District} of Washington, concordou com o pedido formulado pelos requerentes, declarando então a inconstitucionalidade da lei de Washington, na medida em que a proibição do suicídio assistido indevidamente dificultaria o exercício da liberdade constitucional alegada. Inicialmente, um painel de três juízes da United States Court of Appeals for the Ninth Circuit reverteu (por dois a um) a decisão original, compreendendo pela constitucionalidade da legislação questionada. Contudo, o Ninth Circuit aceitou analisar o caso novamente, en banc ${ }^{6}$; em uma decisão por sete a quatro, com o entendimento vencedor redigido pelo Judge Stephen

\footnotetext{
1 Wash. Rev. Code, $\S 9^{a} .36 .060(1)$ (1994) A person is guilty of promoting a suicide attempt when he knowingly causes or aids another person to attempt suicide.

2 Uma organização sem fins lucrativos que ajuda, acompanha e aconselha pessoas que consideram recorrer ao suicídio assistido. A Compassion in Dying não participou do recurso à SCOTUS.

3 Os pacientes participaram do processo sob os pseudônimos John Doe, Jane Roe e James Poe respectivamente, um pintor de 44 anos diagnosticado com AIDS, uma pediatra de 69 anos com câncer de mama e um representante de vendas de 69 anos com doença pulmonar (TESTA, 1998, p.823). Todos eles já estavam mortos quando o caso foi decidido pela Suprema Corte dos Estados Unidos.

4 Quando o caso chegou à SCOTUS, o Dr. John Geyman, um dos médicos, já não estava mais no processo. Os quatro que continuavam na ação quando a questão foi decidida pela Suprema Corte foram os doutores Harold Glucksberg, Abigail Halperin, Thomas A. Preston e Peter Shalit, todos médicos praticantes no estado de Washington.

5 A seção 01 da Décima Quarta Emenda estabelece: "All persons born or naturalized in the United States, and subject to the jurisdiction thereof, are citizens of the United States and of the State wherein they reside. No State shall make or enforce any law which shall abridge the privileges or immunities of citizens of the United States; nor shall any State deprive any person of life, liberty, or property, without due process of law; nor deny to any person within its jurisdiction the equal protection of the laws. (grifo nosso)" A Due Process Clause se trata do trecho grifado, que pode ser traduzido livremente para "nenhum estado privará qualquer pessoa da sua vida, liberdade ou propriedade sem o devido processo legal".

6 Um judicial panel, comum em cortes de apelação nos Estados Unidos, é uma comissão de magistrados que decidem os recursos, análoga a uma turma ou câmara de tribunais brasileiros. Por outro lado, em um julgamento en banc, o caso é arguido perante todos os magistrados da corte, o que é análogo a uma sessão plenária no Brasil.
} 
Reinhardt, a corte confirmou o entendimento do juízo de piso. O estado de Washington decidiu recorrer.

O feito, então, chegou à Supreme Court of the United States, que analisou o caso à luz da seguinte questão: a proibição imposta pelo estado de Washington à conduta de provocar ou ajudar o suicídio alheio viola a Décima Quarta Emenda da Constituição estadunidense? Mais especificamente, a "liberdade" protegida pela Due Process Clause inclui um direito a cometer suicídio que, por sua vez, inclui um direito a receber assistência no referido ato? Deve ser destacado que a análise acerca da inconstitucionalidade da lei questionada foi feita em abstrato; os pacientes anônimos já tinham morrido quando o caso chegou à Corte, o Compassion in Dying não participou do recurso à SCOTUS e os médicos subsistentes na demanda não eram réus em (nem ameaçados concretamente por) ações penais envolvendo a matéria. Desse modo, a SCOTUS apenas analisou se a lei proibindo o suicídio assistido era inconstitucional on its face, ou seja, de forma genérica, em relação a todos ou à maioria dos casos em que poderia ser aplicada; o julgamento não disse respeito a casos concretos, em que a aplicação da norma poderia ser especificamente e particularmente inconstitucional. O governo federal dos Estados Unidos interveio no feito como amicus curiae, alegando tanto que a Due Process Clause protegia um direito a ter alívio de severa dor ou sofrimento, quanto que devia caber às leis estaduais lidar com a questão (GRABOYESRUSSO, 1997, p.909). Ressalte-se ainda que, na mesma oportunidade, a Corte também se debruçou sobre um caso semelhante, julgado separadamente, Vacco v. Quill, no qual se discutiu a constitucionalidade da proibição do suicídio assistido por New York, considerando que aquele estado reconhecia o direito a recusa de intervenções médicas que mantivessem o paciente vivo. Em Vacco v. Quill, a Suprema Corte decidiu pela constitucionalidade da lei nova-iorquina, distinguindo a recusa de tratamento, de um lado, e a assistência ao suicídio, de outro lado - sendo tal distinção suficiente para tratamentos normativos significativamente diferentes.

Quando Washington v. Glucksberg foi julgado pela Suprema Corte, em 1997, o tribunal estava razoavelmente equilibrado em matéria de tendências político-ideológicas, no binômio conservadorismo-progressismo. $\mathrm{Na}$ ala fortemente conservadora, havia o Chief Justice William H. Rehnquist, assim como os ultraconservadores Justices Antonin Scalia e Clarence Thomas. Entre os conservadores moderados se encontravam a Justice Sandra Day O’Connor e o Justice Anthony M. Kennedy. Na ala liberal-progressista, estavam os Justices John Paul Stevens, Ruth Bader Ginsburg, David Souter e Stephen Breyer. 
Em Washington v. Glucksberg, a Supreme Court of the United States entendeu, por unanimidade, que a proibição do suicídio assistido pela legislação do estado de Washington não violava a Due Process Clause da Constituição estadunidense. Apesar de todos os Justices terem chegado à mesma conclusão, no sentido de reconhecer a constitucionalidade da norma então questionada, foram apresentados fundamentos distintos para o julgamento. A opinião da maioria foi redigida pelo Chief Justice Rehnquist, a quem se juntaram os Justices O'Connor, Scalia, Kennedy e Thomas. Além de aderir à opinião majoritária, a Justice O'Connor apresentou também em apartado uma opinião própria, à qual os Justices Ginsburg e Breyer aderiram. Apesar de os Justices Stevens, Souter, Ginsburg e Breyer terem concordado com o resultado do julgamento, cada um apresentou a própria fundamentação.

\section{A OPINIÃO MAJORITÁRIA}

Todos os Justices da Suprema Corte dos Estados Unidos compreenderam pela constitucionalidade da legislação do estado de Washington; entretanto, chegaram a tal conclusão por fundamentos distintos. A fundamentação utilizada pela maioria da Corte foi redigida pelo Chief Justice Rehnquist, com adesão dos Justices O'Connor, Scalia, Kennedy e Thomas. Seu voto teve três pilares: em primeiro lugar, a tradição anglo-americana de proibição do suicídio; em segundo lugar, a inexistência, entre os interesses protegidos pela Due Process Clause da Constituição, de uma liberdade a cometer suicídio; por fim, a fundamentação racional da legislação de Washington em interesses governamentais legítimos.

O Chief Justice Rehnquist iniciou a sua fundamentação situando o suicídio assistido no contexto da história, da tradição legal e da prática jurídica nos Estados Unidos. Aduziu que a assistência ao suicídio é criminalizada em quase todos os estados - e em praticamente todas as democracias ocidentais -, o que denota um longevo compromisso com a proteção e a preservação da vida humana (WASHINGTON, 1997, p.710). Afirmou, no mesmo sentido, que a oposição (à assistência) ao suicídio é consistente com as heranças filosóficas, legais e culturais estadunidenses. Destacou que, por mais de 700 anos, a tradição da common law inglesa vem desaprovando e punindo tanto o suicídio quanto o auxílio ao suicídio; e que essa postura da common law foi em grande parte adotada inicialmente pelas colônias norteamericanas e, posteriormente à Independência, pelas legislações e cortes estaduais. Ressaltou, em especial, que à época da ratificação da Décima Quarta Emenda, praticamente todos os 
estados criminalizavam o ato de assistir alguém a cometer suicídio (WASHINGTON, 1997, p.711-715).

O Chief Justice Rehnquist continuou sua análise observando que os avanços na medicina e na tecnologia vinham recentemente suscitando o debate público sobre como proteger a dignidade e a autonomia no fim da vida, o que resultara em modificações legislativas em matérias sobre testamentos vitais, tomada de decisão substituta e interrupção de tratamentos médicos; todavia, de forma majoritária os eleitores e os legisladores continuavam a reafirmar as proibições ao suicídio assistido. O próprio estado de Washington tinha revisado suas leis criminais em 1975, com a criminalização da assistência ao suicídio; quatro anos depois, a mesma jurisdição aprovara o Natural Death Act, que especificamente diferenciava a interrupção de intervenção médica (legalizada) e o suicídio assistido (proibido). Semelhantemente, em 1991 os eleitores daquele estado rejeitaram nas urnas uma iniciativa que, se aprovada, teria permitido que médicos, a pedido, ajudassem pacientes a morrer de forma digna e humana, sem dor; na sequência, o Natural Death Act foi emendado para expressamente excluir o suicídio assistido das suas provisões (WASHINGTON, 1997, p.716717). O Chief Justice ainda sublinhou que, em abril de 1997, o presidente Bill Clinton sancionara uma lei que proibia o uso de verbas federais para financiamento de práticas de suicídio assistido. Concluiu então a primeira parte da sua opinião estabelecendo que o sistema jurídico estadunidense tem historicamente condenado, e continuava então proibindo, o suicídio assistido; apesar das mudanças nas tecnologias médicas e na ênfase à autonomia para tomada de decisões no fim da vida, não havia um consistente afastamento de tal posicionamento (WASHINGTON, 1997, p.718-719).

Na segunda parte da opinião majoritária da Corte, o Chief Justice Rehnquist analisou se na Due Process Clause da Décima Quarta Emenda à Constituição estadunidense havia uma liberdade de cometer suicídio e de ser assistido nessa conduta. Iniciou afirmando que a liberdade protegida pela Due Process Clause incluía mais do que simplesmente a ausência de restrições físicas; ela também assegurava proteção reforçada contra a interferência estatal com certos interesses e direitos fundamentais. Por outro lado, sustentou que a Supreme Court of the United States sempre fora relutante e cautelosa nos casos em que tinha de expandir a proteção constitucional da Décima Quarta Emenda a novos direitos e interesses, na medida em que a discussão estaria situada fora do debate público e da ação legislativa. Por essa razão, foi estabelecido um método de duas etapas para julgamentos do tipo: primeiramente, a Corte reconhecia a proteção a direitos e liberdades fundamentais que estivessem profundamente 
enraizados na tradição e na história norte-americana; ademais, seria necessária uma cuidadosa descrição do interesse fundamental tutelado (WASHINGTON, 1997, p.719-721).

A partir da questão discutida pela Corte - se na Due Process Clause havia a proteção à liberdade de cometer suicído, que incluía o direito a ser assistido ao fazê-lo -, o Chief Justice Rehnquist passou a refletir se o alegado interesse estava profundamente enraizado na tradição e na história estadunidense. Suscitando os argumentos levantados na primeira parte da sua opinião, ele sustentou que havia uma consistente e quase universal tradição de rejeição ao suicídio assistido, ainda que em relação a adultos plenamente capazes e acometidos de doenças terminais. Nesse sentido, uma decisão pela inconstitucionalidade da lei de Washington exigiria a reversão de séculos de doutrina e prática jurídicas, além da superação das políticas legislativas de quase todas as jurisdições estaduais (WASHINGTON, 1997, p.723). Alegou que, embora muitos direitos e liberdades tuteladas pela Due Process Clause fossem embasados na autonomia individual, daí não decorria que toda e qualquer decisão importante, íntima e pessoal fossem constitucionalmente protegidas (WASHINGTON, 1997, p.727). Desse modo, como o suicídio assistido não estava enraizado na tradição jurídica nacional, não seria possível reconhecê-lo como uma liberdade fundamental (WASHINGTON, 1997, p.728).

Finalizando a reflexão sobre a constitucionalidade da lei do estado de Washington, o Chief Justice Rehnquist aduziu que a Constituição exige uma relação racional entre a proibição legal e interesses estatais legítimos - o que, segundo ele, estava inquestionavelmente demonstrado no caso em questão (WASHINGTON, 1997, p.728). Em primeiro lugar, o estado tinha um interesse em preservação da vida humana; o estado de Washington insistia que toda vida humana, independentemente das condições físicas ou mentais de cada indivíduo, merecia total e igual proteção legal (WASHINGTON, 1997, p.728-729). Em segundo lugar, havia o interesse na prevenção do suicídio, que consistia em um sério problema de saúde público, em especial em relação a grupos vulneráveis; segundo o Chief Justice Rehnquist, a legalização do suicídio assistido poderia tornar mais difícil a proteção estatal a pessoas deprimidas ou com doenças mentais, além daquelas que estejam sofrendo com dor sem o devido tratamento (WASHINGTON, 1997, p.730-731). Em terceiro lugar, havia o interesse estatal de proteger a integridade e a ética da promissão médica; diversas associações profissionais, inclusive a American Medical Association, haviam sustentado que o suicídio assistido era fundamentalmente incompatível com o papel do médico; e a assistência ao suicídio poderia abalar a confiança essencial à relação médico- 
paciente, borrando a linha distintiva entre curar e causar o mal (WASHINGTON, 1997, p.731). Em quarto lugar, havia o interesse estatal de proteger grupos vulneráveis - inclusive os pobres, os mais velhos e as pessoas com deficiência - contra abusos, negligência e erros. $\mathrm{O}$ Chief Justice aduziu serem reconhecidos os riscos reais de coerção e influência indevida nas situações de fim de vida; alegou que muitas pessoas poderiam recorrer ao suicídio assistido para aliviar suas famílias dos elevados custos dos tratamentos de saúde (WASHINGTON, 1997, p.731-732). Em quinto lugar, o estado tinha o interesse de proteger pacientes terminais contra preconceito, estereótipos negativos e indiferença social; a proibição ao suicídio assistido refletia e reforçava a política de que a vida daqueles pacientes não deveria ser menos valorizada do que a de pessoas jovens e saudáveis; além disso, os impulsos suicidas de tais pacientes deveriam ser interpretados e tratados da mesma forma que os de qualquer outra pessoa (WASHINGTON, 1997, p.732). Por fim, em sexto lugar, o estado poderia recear que a permissão ao suicídio assistido acabaria resultando na legalização da eutanásia, tanto voluntária quanto involuntária; o que inicialmente seria uma autorização limitada à ajuda do médico aos pacientes que desejassem se suicidar acabaria se tornando, na prática, uma licença muito mais ampla, que potencialmente seria extremamente difícil de policiar e conter (WASHINGTON, 1997, p.732-733). O Chief Justice Rehnquist concluiu que não precisava definir os pesos exatos de cada interesse, na medida em que todos eram inquestionavelmente legítimos e importantes, além de razoavelmente relacionados com a legislação de Washington, então questionada (WASHINGTON, 1997, p.735).

\section{AS OPINIÕES CONCORRENTES COM O JULGAMENTO}

Além da opinião do Chief Justice Rehnquist, as Justices O'Connor e Ginsburg e os Justices Stevens, Souter e Breyer apresentaram cada um as suas próprias opiniões, concordando com o resultado do julgamento, porém utilizando fundamentação e argumentos distintos.

Em primeiro lugar, a Justice O'Connor apresentou a sua opinião concorrente, à qual aderiram os Justices Ginsburg e Breyer. Ela aduziu que, como a maioria da Corte havia analisado o caso à luz da questão de haver ou não um direito constitucional a cometer suicídio, ela aderia à opinião majoritária, uma vez que concordava com a inexistência de tal direito, em sentido amplo. Entretanto, ela ressaltou que Glucksberg e os demais haviam requerido também uma análise mais restrita, no sentido de se pessoas capazes, que estão 
passando por grande sofrimento, tinham o interesse constitucional de controlar as circunstâncias de suas iminentes mortes. Tratava-se de uma pergunta distinta daquela que a Corte estava então respondendo, e que continuava em aberto. Contudo, para a Justice O’Connor, não havia a necessidade de entrar em tal questão específica no questionamento abstrato à legislação de Washington, na medida em que naquele estado um paciente terminal em grande dor não enfrentava qualquer obstáculo para obter de um médico os remédios ou tratamentos necessários para aliviar o seu sofrimento. Por essa razão, nesse contexto específico em que os cuidados paliativos eram plenamente acessíveis, ainda que a Corte viesse a reconhecer futuramente o direito constitucional ao controle das circunstâncias da própria morte iminente, a Justice O'Connor entendia que a proibição do suicídio assistido estava suficientemente justificada pelos interesses estatais em proteger as pessoas incapazes, ou que não estivessem em situação de morte iminente, ou cujas decisões não fossem verdadeiramente voluntárias (WASHINGTON, 1997, p.736-738). A Justice Ginsburg apresentou uma breve opinião em apartado, apenas aduzindo que utilizaria os fundamentos ora levantados pela Justice O'Connor tanto na decisão de Washington v Glucksberg quanto em Vacco v Quill (WASHINGTON, 1997, p.789).

O Justice Stevens também apresentou uma extensa opinião em apartado, destacando que escrevia separadamente para esclarecer que ainda havia espaço para debates posteriores sobre os limites impostos pela Constituição aos poderes de cada estado de punir o suicídio assistido (WASHINGTON, 1997, p.738). Inicialmente, ele destacou que a Corte estava afastando a alegação de inconstitucionalidade da legislação de Washington on its face, porém isso não impediria que, no futuro, pudesse ser decidido que em alguns casos específicos a aplicação da lei violasse a Constituição. Consignou que, como os três pacientes que subscreveram o pedido inicial tinham morrido após a decisão da District Court, tanto a Court of Appeals quanto a própria Supreme Court of the United States não tinham diante de si qualquer requerente individual solicitando autorização para ser assistido no próprio suicídio, nem qualquer médico ameaçado de persecução criminal por ter auxiliado no suicídio de algum paciente; consequentemente, as respectivas análises e decisões não estavam circunscritas a um grupo específico de requerentes (WASHINGTON, 1997, p.739). Observou que, conforme a jurisprudência da SCOTUS, em casos de inconstitucionalidade de uma lei on its face, o requerente deve estabelecer que em nenhuma circunstância a norma poderia ser válida, o que não estava satisfeito no caso (WASHINGTON, 1997, p.740). Por essa razão, o Justice Stevens aderia ao entendimento da Corte de que a Due Process Clause não contém 
uma liberdade de cometer suicídio que abranja o direito a ser assistido ao fazê-lo. Contudo, deixou claro que a decisão, mantendo a proibição genérica ao suicídio assistido, não significava de modo algum que toda e qualquer aplicação da norma seria válida; era necessário reconhecer que havia situações nas quais o interesse em acelerar a morte poderia tanto ser legítimo quanto digno de proteção constitucional (WASHINGTON, 1997, p.741742). Citando o caso Cruzan, ${ }^{7}$ o Justice Stevens alegou que algumas intervenções estatais no direito de decidir como morrer podem ser consideradas intoleráveis; nesse sentido, alguns indivíduos que estejam no limiar da morte podem ter reconhecido para si um direito constitucionalmente protegido de decidir sobre a própria morte, direito este que pode suplantar o interesse estatal em preservar a vida a qualquer custo (WASHINGTON, 1997, p.745).

O Justice Stevens na sequência questionou um a um os interesses alegados pelo estado de Washington para sustentar a proibição ao suicídio assistido - e que foram utilizados na fundamentação da opinião redigida pelo Chief Justice Rehnquist -, aduzindo que eles não teriam a mesma força em todos os casos. Primeiramente, destacou que o interesse genérico na preservação da vida humana não deve sempre prevalecer sobre interesses particulares de alguém cuja vida esteja sendo intolerável em razão de dor ou qualquer outro sofrimento. Nesse sentido, sustentou que deveria caber ao indivíduo as decisões sobre a qualidade da própria vida e as escolhas do último capítulo para a própria história (WASHINGTON, 1997, p.745-547). Semelhantemente, o interesse do estado em prevenir o suicídio e em proteger os vulneráveis contra abuso e coerção não se aplicaria a casos concretos em que o indivíduo claramente não é vítima desses males e é capaz de tomar uma decisão racional e verdadeiramente voluntária de buscar assistência para cometer suicídio; para indivíduos assim, os alegados interesses estatais estariam minimamente implicados (WASHINGTON, 1997, p.747-748). Em relação ao interesse na preservação da integridade da profissão médica, o Justice Stevens alegou que, para alguns pacientes, a inconsistência com o dever ético do médico consistiria justamente na recusa em fazer as suas mortes toleráveis e dignificadas (WASHINGTON, 1997, p.748). Em suma, embora todos os alegados interesses são suficientes para fundamentar a legislação genericamente proibindo o suicídio assistido, eles

7 CRUZAN by Cruzan v. Director, Missouri Department of Health, 497 US 261 (1990). No caso Cruzan, a Suprema Corte dos EUA entendeu, por um lado, que na Due Process Clause havia um interesse fundamental consistente na liberdade de recusar tratamento indesejado, ainda que tal intervenção médica fosse indispensável à manutenção da vida do paciente; ao mesmo tempo, por outro lado, a referida liberdade poderia ser restringida com base em interesses estatais relevantes. 
nem sempre irão prevalecer sobre os interesses alegados por um indivíduo em particular; desse modo, havia a possibilidade de, no futuro, as alegações de um paciente querendo acelerar a própria morte, ou de um médico querendo prestar a devida assistência, poderiam prevalecer em relação aos interesses estatais em um questionamento particularizado sobre a validade da norma (WASHINGTON, 1997, p.749-750).

O Justice Souter também apresentou a própria (e muito longa) opinião, concordando com o resultado do julgamento, porém rejeitando os fundamentos utilizados pela maioria (WASHINGTON, 1997, p.752). Iniciou estabelecendo que os médicos requerentes não pediram um direito genérico de acelerar mortes iminentes de pacientes, e sim para ajudar aqueles que, de um lado, tenham feito decisões pessoais sobre os próprios corpos e sobre o futuro das suas vidas e, de outro lado, tenham concluído de forma responsável e justificada que o restante das suas existências já teria virtualmente perdido todo o valor para eles; ressaltou ainda que tais médicos requerentes admitiam que o estado poderia regular razoavelmente as suas condutas, de modo a assegurar que os pacientes cujo suicídio fosse assistido realmente tivessem a devida capacidade, estivessem em estado terminal e fizessem uma escolha livre e informada (WASHINGTON, 1997, p.753-754). Aduziu que o estado de Washington insistia, em primeiro lugar, que a autorização para assistência ao suicídio traria diversas consequências adversas e, em segundo lugar, que sua legislação legitimamente visava a prevenção de tais consequências; nesse sentido, o argumento estatal não era negar os direitos dos pacientes, porém que qualquer tentativa de restringir o suicídio assistido às circunstâncias descritas pelos requerentes seria muito provavelmente destinada a falhar; desse modo, o reconhecimento da liberdade individual alegada colocaria em risco as vidas de pessoas fora da classe de pacientes especificamente suscitada naquela ação, criando-se o risco de suicídios irresponsáveis, bem como de eutanásia (WASHINGTON, 1997, p.754-755).

O Justice Souter consignou que os médicos requerentes alegavam que o estado de Washington não tinha qualquer justificativa substancialmente adequada para proibir a assistência procurada pelos pacientes. Também ressaltou que o objeto da demanda era um dos direitos não expressos, porém alegadamente inseridos na Due Process Clause (WASHINGTON, 1997, p.756). Observou que os requerentes embasaram seu pedido em três argumentos: na descriminalização da conduta de cometer suicídio (que na common law antiga era um crime, o que foi abandonado pelas legislações estaduais estadunidenses); na ideia de que a descriminalização da assistência ao suicídio daria ao indivíduo uma liberdade de escolha assemelhada àquela existente em outras áreas da autonomia corporal, ainda que em 
matérias que o Estado opte por desencorajar (como, por exemplo, o aborto); e no tradicional direito à assistência e aconselhamento médicos, sempre subordinado às limitações da escolha informada e responsável e da morte iminente (WASHINGTON, 1997, p.781). O Justice Souter sustentou que a importância do interesse individual alegado pelos requerentes não poderia ser negada; aduziu que o referido interesse de fato demanda um escrutínio cauteloso em relação aos fundamentos das restrições impostas pela legislação; entretanto, consignou estar satisfeito com os interesses trazidos pelo estado de Washington, entendendo que eram suficientemente sérios para afastar a alegação de que a lei contestada seria arbitrária ou despropositada (WASHINGTON, 1997, p.782).

O Justice Souter descreveu que o estado de Washington trouxera diversos interesses para justificar a sua legislação, em especial a proteção genérica à vida, o desencorajamento do suicídio e a proteção aos pacientes contra a eutanásia e o suicídio involuntário. Segundo ele, esse último fundamento seria suficiente, na medida em que invocava um relevante interesse estatal na proteção (a) de indivíduos incapazes e (b) daqueles que não se encontram em uma posição em relação (b1) à morte ou (b2) aos seus médicos que se assemelhe àquela circunstância especificamente descrita pelos requerentes. $\mathrm{O}$ estado argumentara o interesse em proteger pacientes contra decisões equivocadas ou involuntárias de terminar a própria vida, bem como a eutanásia (voluntária ou involuntária). O Justice Souter reconheceu as dificuldades de definir claramente o que é morte iminente; as possíveis decisões equivocadas decorrentes de cuidados paliativos inadequados ou de diagnósticos terminais errados; a coerção e o abuso que podem surgir dos enormes custos com os cuidados médicos; a possibilidade de os médicos, uma vez autorizados a prescrever medicação fatal, deixarem de adequadamente distinguir os pacientes que querem dos que não querem cometer suicídio, bem como aqueles que são capazes dos que são incapazes de tomar uma decisão nesse sentido, além daqueles que são terminais daqueles que estão sofrendo muito sem estar em estado terminal. Desse modo, o Justice Souter concordou com a argumentação de Washington, de que o pedido dos requerentes não era tão estreito quanto se alegava, na medida em que, na prática, haveria consequências que o estado legitimamente poderia querer evitar (WASHINGTON, 1997, p.782-783). Da mesma forma, compreendeu que seria muito difícil estabelecer os mesmos limites impostos para outros direitos relativos à autonomia corporal; de um lado, depender da autovigilância e do autocontrole dos médicos não seria suficiente para evitar que os limites fossem extrapolados; ademais, essa dificuldade se acentuaria considerando que a compaixão dos médicos poderia os tornar mais suscetíveis aos desejos dos 
pacientes, independentemente de estes pacientes se enquadrarem ou não na categoria cuja escolha é defendida pelos requerentes da ação; além disso, a barreira entre o suicídio assistido e a eutanásia seria muito porosa, uma vez que os médicos poderiam muito bem simplesmente administrar as drogas fatais em vez de as entregar aos pacientes; no fim, isso seria uma grande bola de neve. Desse modo, o Justice Souter destacou que existia um plausível argumento no sentido de que o direito alegado pelos requerentes não poderia na prática ser restrito exclusivamente aos fatos por eles aduzidos (WASHINGTON, 1997, p.784-785).

Segundo o Justice Souter, não é possível exercer o judicial review quando as seguintes condições são atendidas: existe uma controvérsia factual séria sobre a viabilidade de reconhecer o direito alegado e ao mesmo tempo impedir que o estado proceda a um inquestionavelmente legítimo exercício do seu poder normativo; os fatos necessários para resolver essa controvérsia não são imediatamente cognoscíveis na esfera judicial; os fatos necessários seriam adequadamente verificados por meio do procedimento legislativo (WASHINGTON, 1997, p.786-787). Para ele, no caso então discutido, os interesses suscitados pelo estado de Washington eram relevantes; era inquestionável a legitimidade da lei para negar a assistência ao suicídio em qualquer outro caso, para além das pessoas capazes e informadas; entretanto, havia uma controvérsia factual relevante sobre a viabilidade de reconhecer o direito suscitado pelos requerentes e, ao mesmo tempo, assegurar que o estado teria a capacidade de proteger todos os pacientes que não se encontrassem nas circunstâncias descritas pelo alegado direito (quais sejam, doença terminal, sofrimento, capacidade, consentimento livre e esclarecido). Conforme o Justice Souter, a resolução da referida controvérsia factual não poderia ser dada judicialmente naquele momento; nesse sentido, os órgãos legislativos tinham meios mais adequados de identificar os elementos necessários para decidir a referida controvérsia, em razão dos seus mecanismos mais flexíveis para coleta e análise de evidências, bem como do poder de modificar as leis à medida que novos fatos forem surgindo (WASHINGTON, 1997, p.787-788).

O Justice Breyer foi o último a apresentar a sua opinião, concordando com as decisões em Glucksberg e em Vacco v Quill. No entanto, ele destacou que discordava do modo como a Corte havia se debruçado sobre o caso (questionando se havia um direito a cometer suicídio com assistência de outrem); para ele, a pergunta que deveria ter sido formulada era se havia um direito a morrer com dignidade (WASHINGTON, 1997, p.789790). Segundo ele, os médicos requerentes haviam alegado que era possível reconhecer um direito a morrer com dignidade, ao se analisar a proteção jurídica a interesses semelhantes 
(porém não idênticos) relacionados à dignidade individual, ao tratamento médico e à liberdade contra intervenções estatais indesejadas (WASHINGTON, 1997, p.791). Todavia, o Justice Breyer aduziu que não acreditava que a SCOTUS precisaria ou deveria, na oportunidade, decidir se tal direito era ou não fundamental; isso porque, na opinião dele, a norma questionada não forçava pacientes terminais a suportar dores físicas severas - pelo contrário, a legislação de Washington permitia que médicos fornecessem aos pacientes medicamentos suficientes para controlar a dor e o sofrimento. Nessas circunstâncias, ele compreendia que a lei de Washington já trazia mecanismos suficientes para rechaçar as alegações suscitadas pelos requerentes (WASHINGTON, 1997, p.791). Assim, ele entendeu que a proibição do suicídio assistido naquele contexto específico não infringia o alegado direito a morrer com dignidade. Por outro lado, admitiu que, se as circunstâncias fossem distintas - por exemplo, se as normas estaduais proibissem a prestação de cuidados paliativos ou de drogas para alívio do desconforto físico -, então poderia ser verificado um impacto direto da legislação nos direitos suscitados. Encerrou, desse modo, afirmando que, nesses casos, a Corte poderia revisitar as conclusões a que estava chegando naquela ação (WASHINGTON, 1997, p.792).

Resumidamente, por 9 votos a zero, por diferentes motivos, a Suprema Corte dos Estados Unidos concluiu que não havia na Due Process Clause um direito ou uma liberdade fundamental de cometer suicídio que tornasse inconstitucional a proibição do suicídio assistido. Por essa razão, a SCOTUS reconheceu a constitucionalidade da lei do estado de Washington que criminalizava a assistência ao suicídio alheio, mesmo que no contexto específico de médicos desejosos de auxiliar pacientes terminais, capazes e sujeitos a grande sofrimento. Destaque-se que a análise sobre a referida legislação se deu on its face, ou seja, de forma genérica, aplicada à totalidade ou à grande maioria dos casos em que a norma poderia ser aplicada; entretanto, a Supreme Court não se debruçou sobre um caso concreto no qual a aplicação da lei poderia ser particularmente e especificamente inconstitucional. Essa circunstância ficou expressamente consignada em diversas passagens ao longo das opiniões juntadas pelos Justices.

\section{REFLEXÕES SOBRE O CASO WASHINGTON V GLUCKSBERG}

O primeiro e talvez mais importante ponto a ser destacado em Glucksberg é a impressionante fragilidade de uma decisão unânime, o que parece ser uma contradição nos 
próprios termos. Todos os Justices concordaram com a decisão final, porém a diversidade de fundamentos leva a questionamentos sobre o que efetivamente foi incluído ou deixado de fora no precedente formado pelo julgamento. Para Yale Kamisar (2008, p.1460), a responsabilidade por isso pode ser em parte atribuída ao Chief Justice Rehnquist, que enquadrou o caso à luz da questão de existir ou não na Due Process Clause uma liberdade de cometer suicídio que incluía um direito a ser assistido ao fazê-lo. Segundo Kamisar, em primeiro lugar, os requerentes não solicitaram o reconhecimento de um direito ao suicídio, apenas da assistência médica ao fazê-lo, na medida em que não havia qualquer proibição ao suicídio em si mesmo em Washington ou em qualquer outro estado; além disso, não se tratava de um pedido genérico de suicídio assistido, somente da assistência em circunstâncias muito extraordinárias (pacientes capazes, terminais e em grande sofrimento). Por conta do enquadramento da questão feito pelo Chief Justice, e por se tratar de um questionamento sobre a constitucionalidade da lei on its face, a Justice O'Connor votou contra o reconhecimento de um genérico direito a cometer suicídio, no que recebeu a adesão do Justice Breyer e da Justice Ginsburg; entretanto, todos manifestaram preocupação específica com os pacientes terminais que estivessem com necessidade de evitar sofrimento (KAMISAR, 2008, p.1461-1462). O Justice Souter não rejeitou peremptoriamente o suicídio assistido, apenas entendeu que com as evidências disponíveis à época, a competência institucional do legislativo estadual para tratar da matéria devia prevalecer. Por fim, o Justice Stevens expressamente consignou que, no futuro, um questionamento não-genérico, aplicado a circunstâncias concretas, poderia ter um resultado distinto, com a prevalência dos interesses individuais dos requerentes sobre os interesses gerais suscitados pelo estado. Por essa razão, apesar da decisão unânime contrária ao suicídio assistido, o conteúdo das opiniões apresentadas permite aduzir que é possível que a SCOTUS, ao julgar não um caso on its face e sim circunstâncias particulares, reconheça que em algumas hipóteses a assistência ao suicídio é constitucionalmente protegida (KAMISAR, 2008, p.1465). Esse mesmo entendimento é adotado por Jennifer Bradford (1998, p.142).

A decisão em Glucksberg recebeu diversas críticas. Antes mesmo de ser tomada, já havia clamores doutrinários fortemente contrários à reversão da decisão do Ninth Circuit com fundamentos na violação tanto da autonomia de decidir sobre a própria vida quanto da dignidade, em razão da inescapabilidade de uma morte com profundo sofrimento (FLEMING, 1997, p.882). Lois Shepherd (1998, p.432-434) destaca que a SCOTUS, em especial a opinião apresentada pelo Chief Justice Rehnquist, de forma negligente praticamente não abordou os 
temas da autonomia e da dignidade, preferindo focar em uma análise da tradição e da história sobre o tema. Para Sheperd, é desapontador que não se tenha discutido as questões de autonomia e dignidade, cujos conteúdos jurídicos precisavam de maior lapidação pela Suprema Corte; ao mesmo tempo, abordá-las não significaria necessariamente uma decisão em favor do suicídio assistido. Ainda segundo Shepherd, é preocupante que a Supreme Court tenha se referido ao reconhecimento de direitos exclusivamente profundamente enraizados na tradição e na história, considerando que na jurisprudência da Corte há exemplos da proteção a direitos fundamentais, como o casamento inter-racial e o aborto, cujo reconhecimento decorreu de batalhas contra as suas longevas proibições.

Alexa Hansen (2008, p.163-164) suscita outra questão que foi negligenciada pela Suprema Corte: o que é a vida e quando ela termina? Para a autora, era fundamental responder a isso, uma vez que, em algum ponto, o interesse estatal na vida de alguém não mais existe, em razão de aquela pessoa não estar mais "viva". Segundo Hansen (2008, p.175), ao deixar de definir "vida", a Supreme Court criou um standard inalcançável: um conceito não definido pode ser abarcado por praticamente qualquer interesse alegado pelo estado. A autora ainda destaca que o significado de vida não é universal, podendo variar de acordo com as circunstâncias; desse modo, o termo é tão vago e aberto a interpretações que é difícil identificar um interesse estatal específico para a sua proteção (HANSEN, 1998, p.177-178).

Erwin Chemerinsky (2008, p.1503-1508) argumenta que a SCOTUS errou ao analisar o caso à luz de uma liberdade contida na Due Process Clause. Para ele, o suicídio assistido deveria ter sido incluído como um desdobramento essencial da autonomia individual sobre o próprio corpo, que decorre especificamente do direito fundamental à privacidade, este por sua vez já reconhecido pela Suprema Corte. O referido autor destaca ser impressionante que nenhum dos Justices tenha suscitado essa questão, que tinha sido o fundamento principal da decisão en banc do Ninth Circuit. Para ele, a corte do Ninth Circuit estava correta: se a privacidade tem algum significado, é justamente a autonomia que as pessoas têm de fazer decisões cruciais a respeito das próprias vidas. Caso a Supreme Court tivesse dessa maneira enquadrado a assistência ao suicídio, a constitucionalidade de qualquer intervenção legislativa nesse direito teria de ser verificada por meio de um strict scrutiny - regras que limitam o direito à privacidade somente são constitucionais se justificadas por interesses estatais irrefutáveis e convincentes (compelling state interests). Como a SCOTUS se recusou a reconhecer o suicídio assistido como direito fundamental, a legislação de Washington passou apenas por uma rational basis review, ou seja, examinou-se se ela estava razoavelmente 
relacionada a um interesse estatal legítimo - o que é mais fácil de ser satisfeito do que o mencionado escrutínio estrito.

Erwin Chemerinsky (2008, p.1505) critica ainda a afirmação feita pelo Chief Justice Rehnquist, no sentido de que somente poderiam ser reconhecidos como fundamentais aqueles direitos e liberdades profundamente enraizados na história e tradição nacionais. $\mathrm{O}$ mencionado autor afirma que a Suprema Corte não vinha atuando seguindo essa linha de pensamento, principalmente no que dizia ao reconhecimento de novos desdobramentos do direito constitucional à privacidade. Por outro lado, Steven G. Calabresi e Sarah E. Agudo (2008, p.13) sustentam que, se se adota a ideia de que a Due Process Clause protege apenas aqueles direitos profundamente enraizados na história e na tradição, um bom ponto de partida para buscar esse conteúdo é o ano de1868, no qual a Décima Quarta Emenda foi ratificada. Observando as constituições estaduais vigentes à época, os referidos doutrinadores (2008, p.118-119) afirmam que elas de modo geral reconheciam direitos implicitamente decorrentes de uma "lei natural", o que significa dizer que qualquer direito considerado inalienável e natural pode ser reconhecido como tutelado pela Due Process Clause - sendo, portanto, falha a interpretação restritiva adotada em Glucksberg.

Deve ser mencionado que, em Cruzan v Director, no início dos anos 1990, a Supreme Court havia reconhecido o direito de recusar tratamento médico, ainda que relativamente a uma intervenção que fosse imprescindível para manter o paciente vivo. Esse precedente foi levado pelos requerentes à SCOTUS; todavia, ele foi distinguido em relação ao suicídio assistido. Essa distinção é claramente baseada na tradição ética do cristianismo, que diferencia o agir para a morte do manter-se passivo (HANAFIN, 2009, p.86).

A Supreme Court deixou aos estados a responsabilidade de legislar sobre o suicídio assistido. De acordo com Jennifer Bradford (1998, p.145-146), não havendo uma regra uniforme sobre a sua permissão ou proibição, alguns estados a legalizaram, outros continuam a criminalizar a conduta e processar médicos que a realizam. Segundo a autora, entre outras dificuldades, isso pode gerar o problema do fórum shopping: indivíduos cruzando divisas estaduais para obter assistência em seus suicídios. Ela ainda destaca a questão de suicídios assistidos continuarem sendo praticados ilegalmente naquelas jurisdições onde a conduta é proibida; nesses estados, a falta de regulamentação (e, consequentemente, de mecanismos protetivos dos pacientes) pode resultar em pressões indevidas ou diagnósticos equivocados.

Em 1997, o estado do Oregon aprovou o Death with Dignity Act, autorizando pacientes terminais a encerrar suas próprias vidas com o uso de medicação letal prescrita por 
um médico especificamente para esse propósito $^{8}$. O paciente deve ter ao menos 18 anos, ser residente no Oregon, capaz de tomar decisões sobre seu estado de saúde e de comunica-las, além de ter sido diagnosticado com uma doença terminal que o levará à morte em até seis meses; compete ao médico determinar se os critérios impostos foram ou não atendidos. Os dados da experiência no Oregon demonstraram que a aplicação da lei não causou os males anteriormente suscitados, além de ter trazido conforto tanto para os doentes terminais que recorrem à prática quanto para aqueles que se confortam sabendo que há essa opção disponível (TUCKER, 2008, p.1594). Hoje, além do Oregon, também há legislações sobre suicídio assistido na California, no Colorado, no District of Columbia, no Hawaii, no Maine, em New Jersey, no New Mexico, em Vermont e no próprio estado de Washington, que saíra vencedor em Glucksberg. Por decisão judicial, também é permitido o suicídio assistido em Montana 9 .

A United States Supreme Court ainda não julgou um caso no qual fosse questionada a constitucionalidade das leis autorizando o suicídio assistido. Segundo Steven B. Datlof (1999, p.34), o resultado de Glucksberg não significa que a SCOTUS consideraria as autorizações inconstitucionais; isso vai depender de a Corte verificar se tais normas violam direitos ou liberdades fundamentais de requerentes solicitando proteção contra o suicídio assistido. Ressalte-se, contudo, que atualmente a composição daquele tribunal é predominantemente conservador, com uma maioria de 6 a 3 sobre os Justices da ala progressista.

Interessante notar que de modo geral os Justices focaram na discussão de pacientes terminais e capazes terem ou não um direito ao suicídio assistido; todos parecem ter partido do pressuposto que tal debate sequer deveria envolver os pacientes que não estavam em estado terminal ou aqueles afetados por doenças mentais. Conforme Yale Kamisar (2008, p.1460), esse recorte não foi ao acaso: os causídicos dos requerentes sabiam que restringir a discussão aos pacientes capazes e terminais seria a sua melhor (talvez a única) chance de sair vitoriosos da demanda, uma vez que um direito tão estreito causaria menos alarme e teria mais apoio do que um direito genérico ao suicídio assistido. Da mesma maneira, Oregon e os demais estados que aprovaram leis nesse sentido de modo geral se limitaram a assegurar tal direito a pessoas capazes e em estado terminal. De todo modo, é possível que tal pressuposto

8 Recomenda-se o estudo dessa lei e das suas regulamentações para quem se interessar pelo suicídio assistido. Destaque-se que em janeiro de 2020 entraram em vigor alterações no regulamento da legislação, em atenção a estudos sobre os limites e possibilidades de aplicação da norma durante o seu período de vigência.

9 Mais informações e recursos sobre o status do suicídio assistido em cada jurisdição estadunidense podem ser encontrados em https://deathwithdignity.org/in-your-state/. 
tenha sido limitado demais: como bem menciona Candice T. Player (2018, p.115-119), algumas jurisdições (Países Baixos, Bélgica, Suíça) permitem o suicídio assistido para pacientes não terminais, desde que acometidos por grave sofrimento físico ou psíquico. Além disso, segundo a mesma autora, a literatura médica tem demonstrado que a doença ou deficiência mental não se confunde com incapacidade, em especial em relação à autonomia de tomar decisões sobre a própria vida. Desse modo, seria interessante a reformulação da discussão sobre a assistência ao suicídio que levasse em consideração os direitos e liberdades dessas outras classes de pacientes. Por essa razão, Katherine C. Glynn (1997, p.354-355) afirma que a constitucionalidade das limitações impostas pelas legislações pode ser questionada, em especial por pacientes graves, porém não-terminais; afinal, assim como os terminais, também eles se encontram em um inimaginável estado de sofrimento e indignidade causado por suas doenças. Além disso, uma distinção característica para os pacientes terminais é que os não-terminais são forçados a viver em dor por períodos de tempo mais longos. Nesse sentido, se o suicídio assistido tem sido legalizado como uma manifestação da proteção contra o sofrimento desumano, é difícil encontrar um fundamento que justifique a sua não-aplicação para aqueles que não são considerados terminais, porém que estão em condição de sério sofrimento (BRADFORD, 1998, p.146).

Por fim, destaque-se que, atualmente, especialistas das áreas médica e jurídica nos Estados Unidos têm rejeitado o uso da expressão suicídio assistido para se referir à escolha feita por pacientes capazes e terminais, no sentido de obter medicação que lhes traga uma morte pacífica e digna. O termo "suicídio" traz uma carga valorativa negativa, além de não corresponder adequadamente à situação ora discutida (TUCKER, 2008, p.1596). Termos mais neutros e menos pejorativos enriquecem a discussão técnica, menos preconceituosa e sensacionalista, e permitem a formação de um esclarecimento mais efetivo por parte dos pacientes. Por essa razão, vem sendo utilizadas expressões como death with dignity - nome da legislação do Oregon, supramencionada - ou medical aid in dying - nome da legislação sobre o tema em vigor no Canadá. Evidentemente, os opositores da prática continuam a denominala suicídio, dando à escolha um caráter maligno e de reprovação.

\section{CONCLUSÃO}

Neste artigo, observou-se que a legislação do estado de Washington criminalizava o ato de assistir alguém a cometer suicídio. Verificou-se que uma ação foi proposta 
questionando a constitucionalidade de tal proibição, em especial no contexto de um paciente capaz, em estado terminal, requerendo assistência de um médico para obter a medicação necessária para acabar sua vida e, consequentemente, encerrar o sofrimento e morrer com dignidade. Percebeu-se que tanto a District Court quanto o pleno da Court of Appeals concordaram com os requerentes, entendendo que a lei violava direitos constitucionais; entretanto, o estado recorreu novamente.

Notou-se que, quando o caso chegou à Supreme Court, o tribunal estava razoavelmente equilibrado em matéria de conservadores e progressistas. Verificou-se que a Corte julgou por unanimidade a favor do estado de Washington, entendendo-se que a lei questionada não era inconstitucional on its face - ou seja, em abstrato, em relação à maioria dos casos à qual ela poderia ser aplicada. Observou-se que, apesar da unanimidade, foram apresentados diversos fundamentos distintos pelos quais os Justices chegaram àquela conclusão.

Identificou-se que a opinião da maioria da Corte foi redigida pelo Chief Justice Rehnquist, que enquadrou o caso à luz da questão: "existe um direito constitucional a cometer suicídio que inclui o direito a ser assistido?”. Percebeu-se que ele embasou sua decisão em três pilares: a histórica condenação ao suicídio, em especial na common law; a inexistência de uma liberdade fundamental de cometer suicídio e, consequentemente, de ser assistido ao fazêlo; e a fundamentação racional da legislação de Washington.

Verificou-se que a Justice O'Connor apresentou a própria opinião, concordando não haver um direito genérico ao suicídio; ela, porém, aduziu que a Corte poderia revisitar a matéria em circunstâncias nas quais os pacientes não tivessem acesso a métodos de aliviar o próprio sofrimento. Destacou-se que o Justice Stevens consignou que, no futuro, a Corte poderia se debruçar novamente sobre a temática, em relação a casos concretos, ou seja, quando a análise não fosse genérica, porém aplicada a um paciente procurando autorização para o suicídio assistido ou a um médico sendo processado por ter praticado a conduta. Notou-se que o Justice Souter compreendeu que os legislativos estaduais estavam equipados com melhores mecanismos para regulamentar a matéria. Por fim, viu-se que o Justice Breyer entendeu que a legislação de Washington não era inconstitucional porque trazia outros mecanismos, que não o suicídio assistido, que afastavam a violação ao direito a morrer com dignidade; entretanto, que a conclusão poderia ser diferente em circunstâncias distintas, caso tais mecanismos não houvessem em outras jurisdições. 
Notou-se que as fundamentações não enfrentaram a fundo o debate sobre autonomia e dignidade no momento da morte, focando em especial no tratamento do suicídio pela tradição e história do direito estadunidense. Compreendeu-se que a diversidade de fundamentações deixou aberto espaço para se discutir futuramente se a proibição do suicídio assistido poderia ser inconstitucional em circunstâncias particulares, não abstratamente. Do mesmo modo, depreendeu-se que a SCOTUS deixou aos estados a responsabilidade de decidir se legalizariam ou proibiriam o suicídio assistido. Também se verificou que a discussão foi centralizada em pacientes terminais e capazes, deixando de enfrentar a questão de pacientes não-terminais em grande sofrimento e de pacientes acometidos por doenças mentais. Verificou-se que atualmente diversos estados norte-americanos têm legislações autorizando o suicídio assistido - e que o fato de haver regramentos distintos em diferentes jurisdições estaduais pode gerar problemas. Por fim, consignou-se que a expressão "suicídio assistido" deve ser substituída por termos que carreguem menos negatividade e preconceito.

\section{REFERÊNCIAS}

BRADFORD, Jennifer. Vacco v. Quill and Washington v. Glucksberg: thou shalt not kill, unless your state permits physician-assisted suicide. Pepperdine Law Review, vol. 26, n. 1, 1998.

CALABRESI, Steven G.; AGUDO, Sarah E. Individual rights under state constitutions when the fourteenth amendment was ratified in 1868: what rights are deeply rooted in American history and tradition? Texas Law Review, vol. 87, 2008.

CHEMERINSKY, Erwin. Washington v.Glucksberg was tragically wrong. Michigan Law Review, vol. 106, n. 8, 2008.

DATLOF, Steven B. Beyond Washington v Glucksberg: Oregon's Death with Dignity Act analyzed from medical and constitutional perspectives. Journal of Law and Health, vol. 14, n. $1,1999$.

FLEMMING, James E. Constitutional tragedy in dying: responses to some common arguments against the constitutional right to die. Fordham Urban Law Journal, vol. 24, n. 4, 1997.

GLYNN, Katherine C. Turning to state legislatures to legalize physician-assisted suicide for seriously ill, non-terminal patients after Vacco v. Quill and Washington v. Glucksberg.

Journal of Law and Policy, vol. 6, n. 1, 1997. 
GRABOYES-RUSSO, Stephanie. Too costly to live: the moral hazards of a decision in Washington v. Glucksberg and Vacco v. Quill. University of Miami Law Review, vol. 51, n. 3, 1997.

HANAFIN, Patrick. Rights of passage: law and the biopolitics of dying. In: BRAIDOTTI, R.; COLEBROOK, C.; HANAFIN, Patrick (eds.). Deleuze and law: forensic futures. Basingstoke, UK: Macmillan Publishers Limited, 2009.

HANSEN, Alexa. Unqualified interests, definitive definitions: Washington v. Glucksberg and the definition of life. Hastings Constitutional Law Quarterly, vol. 36, n. 1, 2008.

KAMISAR, Yale. On the meaning and impact of the physician-assisted suicide cases. University of Michigan Law School Scholarship Repository, 1998.

KAMISAR, Yale. Can Glucksberg survive Lawrence? Another look at the end of life and personal autonomy. University of Michigan Law School Scholarship Repository, 2008.

MILLER, Margaret P. Boot-strapping down a slippery slope in the second and ninth circuits: compassion in dying is neither compassionate nor constitutional. Creighton Law Review, vol. 30, 1997.

PLAYER, Candice T. Death with dignity and mental disorder. Arizona Law Review, vol. 60, 2018.

SHEPHERD, Lois. Dignity and autonomy after Washington v. Glucksberg: an essay about abortion, death, and crime. Cornell Journal of Law and Public Policy, vol. 07, n. 2, 1998.

TESTA, Nicole. Sentenced to life? An analysis of the United States Supreme Court's Decision in Washington v. Glucksberg. Nova Law Review, vol. 22, n. 3, 1998.

TUCKER, Kathryn L. In the laboratory of the states: the progress of Glucksberg's invitation to states to address end-of-life choice. Michigan Law Review, vol. 106, n. 8, 2008.

WASHINGTON et al. v. Glucksberg et al., 521 US 702 (1997). 